\title{
Radiological appearances of ulcerative colitis: an evaluation of their clinical significance
}

\author{
F. T. de DOMBAL, N. GEFFEN, A. DARNBOROUGH, G. WATKINSON, \\ AND J. C. GOLIGHER ${ }^{1}$ \\ From the Colitis Clinic of the Professorial Surgical Unit, and the Diagnostic X-ray Department, \\ The General Infirmary at Leeds
}

Many groups of workers have investigated the radiological changes of ulcerative colitis, and yet considerable difficulty still remains in the interpretation of these changes. Perhaps this is due to the fact that most studies have concentrated upon a detailed description of the radiological findings, whilst only a few have attempted to assess their significance in terms of the subsequent fate of the patient.

Indeed, what is the clinical significance of the various radiological appearances of ulcerative colitis? The present paper attempts to evaluate this problem by comparing the findings on each of 340 barium enemas with the clinical pattern of colitis in each case.

We have previously shown that many radiological signs described as being typical of colitis are open to wide variation in individual interpretation (Geffen, Darnborough, de Dombal, Watkinson, and Goligher, 1968). In this paper we shall attempt to answer three further questions. Do the radiological findings accurately reflect the clinical pattern of colitis? Is it possible to give an accurate short or long term prognosis on the basis of the $x$-ray appearances? And, finally, what are the radiological signs upon which such a prognosis may be based?

\section{CLINICAL MATERIAL AND METHODS}

The radiological studies reported in this paper were carried out on 465 patients with ulcerative colitis who presented to a combined medico-surgical colitis clinic at Leeds between 1952 and 1963. During the latter half of 1963 all patients were traced and all but eight of the 424 survivors were personally interviewed. The clinical course of colitis in these patients has been reported in detail elsewhere (Watts, de Dombal, Watkinson, and Goligher, $1966 \mathrm{a}$ and $\mathrm{b}$ ).

During this period of time, 340 barium enemas were performed on these patients in the diagnostic $x$-ray department of the Leeds General Infirmary. In all 278 patients underwent one or more barium enemas. The

'Address for reprints: Prof. J. C. Goligher, University Department of Surgery, The General Infirmary at Leeds. other patients, who either had rectal disease alone as judged at repeated sigmoidoscopy (24 patients), or who came to urgent surgery during their first referred attack (94 patients), or whose barium studies were performed elsewhere (69 patients), have been excluded from the present report.

The barium enemas were performed using barium sulphate, or in the case of the more recent enemas, Micropaque. Occasionally tannic acid was added to the enema. Films were taken in the standard projections, both before and after the evacuation of the radioopaque material; and in most cases air-contrast studies were then performed.

For the purposes of the present report, the investigation was carried out in three phases.

PHASE ONE The films from each examination were examined in retrospect and assessed by two radiologists working together; and in each case the presence or absence of the various radiological signs of ulcerative colitis was noted. Both of the radiologists were especially interested in gastrointestinal disease; and neither was aware of any clinical details until the completion of the survey.

The radiological signs which were investigated are listed in Table I. A number of other signs described in connexion with ulcerative colitis were considered to be unreliable on the basis of previous observer variation studies (Geffen et al., 1968), and are not analysed here.

TABLE I

RADIOLOGICAL SIGNS OF ULCERATIVE COLITIS EVALUATED IN THIS REPORT

\begin{tabular}{|c|c|c|}
\hline General Signs & Filled Film & $\begin{array}{l}\text { Post-evacuation } \\
\text { Film }\end{array}$ \\
\hline $\begin{array}{l}\text { Decreased length } \\
\text { Decreased tone } \\
\text { Decreased calibre } \\
\text { Decreased distensibility }\end{array}$ & $\begin{array}{l}\text { Absent haustration } \\
\text { Ulceration } \\
\text { Double contour } \\
\text { Fine serration }\end{array}$ & $\begin{array}{l}\text { Longitudinal folds } \\
\text { Polyps } \\
\text { Abnormal haustra }\end{array}$ \\
\hline
\end{tabular}

PHASE TWO An independent assessment was then made of the clinical pattern of disease at the time of each barium enema. Four parameters were recorded in each instance, these being, (1) the duration of colitic symp- 
TABLE II

THF CLINICAL PATTERN OF COLITIS AT THE TIME OF EACH OF 340 BARIUM ENEMAS

\begin{tabular}{|c|c|c|c|c|c|c|c|}
\hline \multirow{2}{*}{\multicolumn{2}{|c|}{ Duration of Symptoms }} & \multirow{2}{*}{\multicolumn{2}{|c|}{ Severity of Colitis }} & \multicolumn{4}{|l|}{ Prognosis } \\
\hline & & & & \multicolumn{2}{|l|}{ Short-term } & \multicolumn{2}{|l|}{ Long-term } \\
\hline Up to I year & $77^{2}$ & Remission & 111 & Good & 230 & Good & 206 \\
\hline $1-4$ years & 97 & Mild attack & 79 & Fair & 52 & Fair & 22 \\
\hline $5-9$ years & 78 & Moderate attack & 76 & Medical failure & 54 & Medical failure & 108 \\
\hline 10 years & 80 & Severe attack & 69 & Unknown & 4 & Unknown & 4 \\
\hline Unknown & 8 & Unknown & 5 & & & & \\
\hline
\end{tabular}

${ }^{2}$ Refers to number of barium enemas in each category.

toms: (2) the maximum severity of colitis (within one month of the enema); (3) the immediate outcome to the patient (at the end of that year); (4) the patient's final outcome (at the time of review in 1963).

The clinical pattern of colitis at the time of each barium enema is shown in Table II. The categories in the duration' parameter are self-explanatory. Attacks of colitis were graded as mild, moderate, or severe according to the criteria of Truelove and Witts (1955). Remission was defined as a state in which the patient's general health was good, and bowel symptoms minimal or absent. The outcome to the patient, in both the short and the long term, was classified as follows:-

Good The patient was in remission.

Fair The patient was having symptoms, but these were insufficient to warrant surgery.

Medical failure Medical treatment failed to control the colitis, and the patient either died or came to radical surgery.

PHASE THRH: Finally an attempt was made to correlate the radiological findings with the clinical picture, to try and determine the clinical significance of each individual radiological sign. All of the signs were investigated in considerable detail, and it is neither possible nor desirable within the limitation of this report to describe each sign in the detail in which it was investigated. It is proposed therefore to treat just one sign (that of ulceration on the filled film) in such an illustrative manner, and then to proceed to a description of the overall findings by considering each of the four clinical parameters.

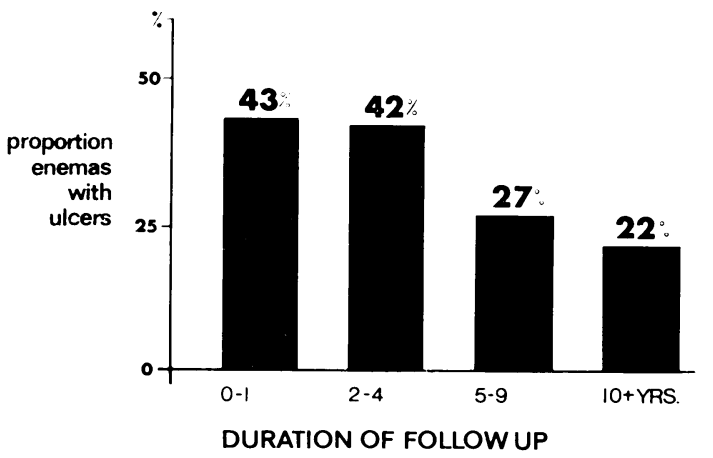

FIG. 1. The relationship between the duration of follow up and the incidence of ulceration on barium enema.
Ulceration on the filled film was noted in 33 of the 77 $(43 \%)$ barium enemas performed within one year of the onset of symptoms (Fig. 1). After this first year, however, the frequency with which this sign was noted steadily decreased, and ulcers were only noted in 18 of the 80 barium enemas performed more than 10 years after the first attack $(22.5 \%)$. This trend is probably of statistical significance $\left(\chi^{2}=7.93, \mathrm{n}=3, \mathrm{P}<0.05\right)$.

The presence or absence of ulceration was related to the activity of colitis at the time (Fig. 2). Ulcers were seen in over half of the barium enemas performed within one month of a severe attack ( 45 out of $76,59 \%$ ). They were less common in moderate or mild attacks, and were only found in $10 \%$ of the enemas performed on patients in remission (seven out of 69). This trend achieves a high degree of statistical significance $\left(\chi^{2}=32 \cdot 84, \quad \mathrm{n}=3\right.$, $P<0.0001)$.

Ulcers were associated with a poor immediate prognosis (Fig. 3). Over half the enemas performed on patients who died or came to surgery within one year showed evidence of ulceration (28 out of $54,52 \%$ ), whereas this sign was much less common in patients whose year ended in remission ( 75 enemas out of 230 , $32 \%$ ). Once again this trend is probably significant statistically $\left(\chi^{2}=7 \cdot 74, \mathrm{n}=2, \mathrm{P}<0.05\right)$.

However, the presence or absence of ulcers had no effect at all on the long-term outlook for the patient at the time of review (Fig. 4). Ulcers were equally likely to be seen on the barium enemas of patients whose long-term outlook was good $(33 \%)$, fair $(32 \%)$, or in whom medical treatment failed $\left(36^{\circ}\right)$.

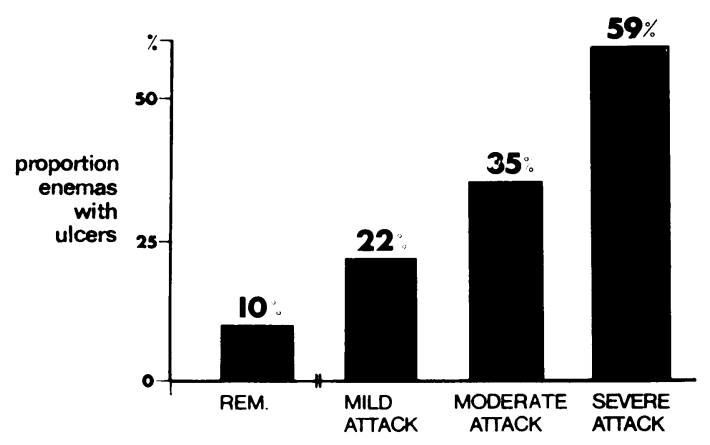

FIG. 2. The relationship between the activity of ulcerative colitis and the incidence of ulceration on barium enema. 


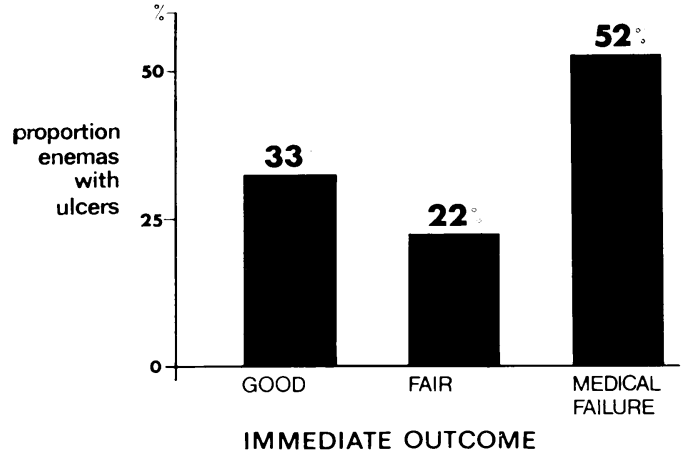

FIG. 3. The relationship between barium enema ulceration and the immediate outcome to the patient.

\section{FINDINGS}

DURATION OF COLITIS The effect of the duration of colitis symptoms on the incidence of each radiological sign is shown in Table III. Most signs were little influenced by the duration of disease, although ulceration was significantly more common in the first few years of colitis $(\mathrm{P}<0.05)$. Conversely, several other signs were found with increasing frequency as the duration of colitis increased; and in the case of four of these signs, this trend achieved statistical significance. These signs were decreased length ( $P$. 0.02), decreased calibre $(P<0.01)$, decreased distensibility $(P<0.01)$, and finally longitudinal folds after evacuation $(\mathrm{P}<0.02)$.

TABLE III

EFFECT OF DURATION OF SYMPTOMS ON RADIOLOGICAL SIGNS OF COLITIS

\begin{tabular}{|c|c|c|}
\hline $\begin{array}{l}\text { Associated with } \\
\text { Short History }\end{array}$ & $\begin{array}{l}\text { Unaffected by Duration } \\
\text { of Symptoms }\end{array}$ & $\begin{array}{l}\text { Associated with Long } \\
\text { History }\end{array}$ \\
\hline $\begin{array}{l}\text { Vicers" } \\
\text { Double contour } \\
\text { Fine serration }\end{array}$ & $\begin{array}{l}\text { Haustra on post- } \\
\text { evacuation film }\end{array}$ & $\begin{array}{l}\text { Decreased calibre }{ }^{2} \\
\text { Decreased length } \\
\text { Decreased distensibility } \\
\text { Longitudinal folds } \\
\text { Absent haustra } \\
\text { Decreased tone } \\
\text { Polyps on P.E. }\end{array}$ \\
\hline
\end{tabular}

"Signs in bold type are those where association is significant statistically.

SEVERITY OF COLITIS Only one sign was associated with inactive colitis (Table IV). A decrease in the length of the colon was more frequently found in remission than during attacks of colitis $(\mathrm{P}<0.05)$.

It may well be thought that most of the radiological signs of ulcerative colitis would be almost exclusively found during attacks of colitis, but Table IV shows that this was not so. In fact, the incidence of most individual signs was little affected

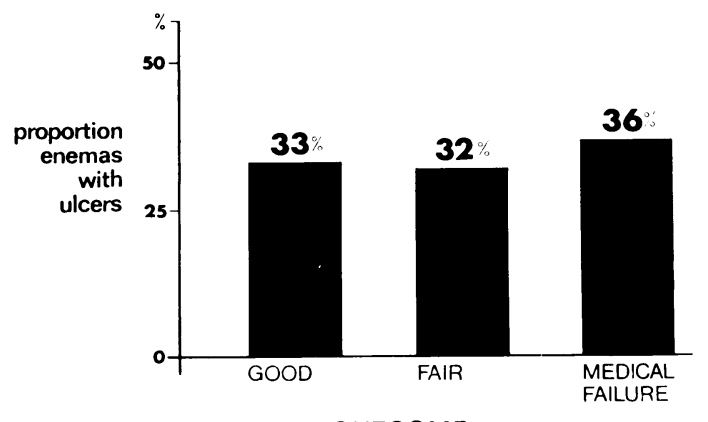

FINAL OUTCOME

FIG. 4. The relationship between barium enema ulceration and the final outcome to the patient.

by the activity of colitis; and, surprisingly, there was only one sign (ulceration), which was significantly associated with severe attacks of colitis ( $\mathrm{P}<0.0001)$. Of the other signs it should be mentioned that double contour was almost always noted during severe attacks of colitis (but the occurrence of this sign was so infrequent that statistical analysis was not possible).

\section{TABLE IV}

EFFECT OF ACTIVITY OF COLITIS ON THE INCIDENCE OF RADIOLOGICAL SIGNS

\begin{tabular}{lll}
$\begin{array}{l}\text { Associated with } \\
\text { Inactive Colitis }\end{array}$ & $\begin{array}{l}\text { Unaffected by Colitic } \\
\text { Activity }\end{array}$ & $\begin{array}{l}\text { Associated with } \\
\text { Active Colitis }\end{array}$ \\
\hline Decreased length & $\begin{array}{l}\text { Decreased calibre } \\
\text { Decreased distensibility }\end{array}$ & $\begin{array}{l}\text { Ulceration } \\
\text { Decreased tone } \\
\text { Double contour }\end{array}$ \\
& $\begin{array}{l}\text { Longitudinal folds } \\
\text { Polyps on P.E. }\end{array}$ & $\begin{array}{l}\text { Fine serration } \\
\text { Absent haustra }\end{array}$ \\
& Haustra on P.E. &
\end{tabular}

${ }^{2}$ Signs in bold type are those where association is significant statistically.

THE IMMEDIATE OUTCOME None of the radiological signs analysed influenced the outcome in a beneficial way by its presence, and this is scarcely surprising (Table V). However, the presence or absence of many signs seemed to make very little difference to the outlook for the patient during that year. Only four radiological signs were significantly associated with a poor short-term outlook for the patient, these signs being ulceration $(\mathrm{P}<0.05)$, fine serration $(\mathrm{P}<0.02)$, decreased tone $(\mathrm{P}<0.02)$, and the presence of polyps after evacuation $(P<0.02)$.

A double contour carried an extremely poor outlook. This sign was noted in almost $10 \%$ of the enemas performed on patients who died or came to surgery within one year, but was very rarely found in enemas performed when the outlook for that year was good. Although this difference cannot be 
analysed statistically because of the small numbers involved, we nevertheless believe that this rare sign has a definite adverse influence on the immediate prognosis.

\section{TABLE V}

THE INFLUENCE OF RADIOLOGICAL SIGNS OF COLITIS ON OUTCOME FOR THAT YEAR

\begin{tabular}{lll} 
Good Prognosis & No Effect on Prognosis & Poor Prognosis \\
\hline & Decreased length & Decreased tone \\
Decreased calibre & Ulceration \\
& Decreased distensibility & Fine serration \\
Absent haustra & Polyps on P.E. \\
& Longitudinal folds & Double contour \\
& Haustra on P.E. &
\end{tabular}

2Signs in bold type are those where association was statistically significant.

It is therefore immediately apparent that any short-term prognosis based upon the radiological findings must depend upon the presence or absence of the following signs: (1) decreased tone, (2) ulceration, (3) fine serration, (4) double contour, and (5) polyps on post-evacuation film.

It must, however, be equally apparent that none of these signs by itself can give more than a rough guide to prognosis in the individual patient. We have therefore investigated these signs further to determine whether a combination of more than one of these signs might not give a more accurate guide to individual prognosis and the results of these studies are shown in Table VI.

TABLE VI

COMBINATION OF SIGNS WITH A POOR IMMEDIATE PROGNOSIS

\begin{tabular}{lccc} 
& \multicolumn{3}{l}{ Outcome for that Year } \\
\cline { 2 - 4 } No. of Signs Present & $\begin{array}{l}\text { Good or } \\
\text { Fair }\end{array}$ & $\begin{array}{l}\text { Medical } \\
\text { Failure }\end{array}$ & $\begin{array}{l}\text { \% Medical } \\
\text { Failure in } \\
\text { Each Group }\end{array}$ \\
\hline Four or Five & 8 & 2 & $80 \cdot 0$ \\
Three & 20 & 10 & $66 \cdot 6$ \\
Two & 16 & 46 & $25 \cdot 8$ \\
One & 8 & 104 & $7 \cdot 1$ \\
None & 2 & 120 & $1 \cdot 7$
\end{tabular}

If none of these signs were present in a barium enema the outlook for the year was excellent and the patient's chance of dying or coming to surgery was less than $2 \%$. If any one of the signs was present by itself, then the outlook for the patient in that year was somewhat worse, the chance of medical failure being just under $8 \%$. But if any two of these signs were present, the outlook was considerably less good. In this situation the patient's chance of dying or coming to surgery rose to $25.8 \%$.

This prognosis is relatively poor, but if three, four, or all five signs were present in the same barium enema, then the patient's outlook became gloomy in the extreme. In this situation, the patient's chances of survival on medical treatment alone were slim, and all but a handful either died or came to surgery within the next few months.

We believe, therefore, that a study of these five signs in combination will give a fairly useful individual prognosis for a colitic patient. If none are present then the short-term outlook for that patient is good, but if three or more are present then the immediate outlook on continued medical treatment is appalling.

THE LONG-TERM PROGNOSIS In complete contrast, of all the signs listed in Table I none influenced the long-term outlook for the patient in a statistically significant way. Of the signs such as ulceration and double contour which influenced the immediate outcome in such a striking manner, we have been immensely impressed by their almost total lack of influence on the long-term prognosis. Ulceration, for example, was found in $33 \%$ of the enemas where the outcome at review was satisfactory, and in $36 \%$ of the enemas where medical treatment subsequently failed.

The only feature radiologically which appears to influence the patient's long-term prognosis is the extent to which the colon and rectum are involved by colitis. We have shown in a previous paper (Watts et al., 1966b) how the extent of involvement by colitis influences the course of the disease, and that the risk to life for a patient with ulcerative colitis varies considerably according to the extent of involvement of the colon.

However, the extent of disease is not necessarily static, and greater or lesser amounts of the colon may be involved in the individual patient with the passage of time. We have therefore paid particular attention to 110 patients in whom serial barium enemas had been performed. Figure 5 shows the results of this analysis.

We have followed 38 patients, in whom there was evidence of disease in the rectum alone at the time of their initial barium examination, for a subsequent mean period of 2.1 years (range 1-8 years). At the time of their most recent barium enema the disease was still confined to the rectum in 23 of the 38 patients $(60.4 \%)$. However, in the remaining 15 patients, the disease had spread to involve substantial areas of the colon $(26.4 \%)$, or even in some cases the whole colon $(13.2 \%)$. Thus during this relatively short follow-up, nearly two-fifths of the patients whose disease was initially confined to the rectum subsequently developed more extensive colitis.

A further 50 patients were seen whose disease initially involved substantial areas of the colon. These patients were followed for a rather longer period (mean 3.0 years, range 1-13 years). At the time of their latest barium enema there was no 


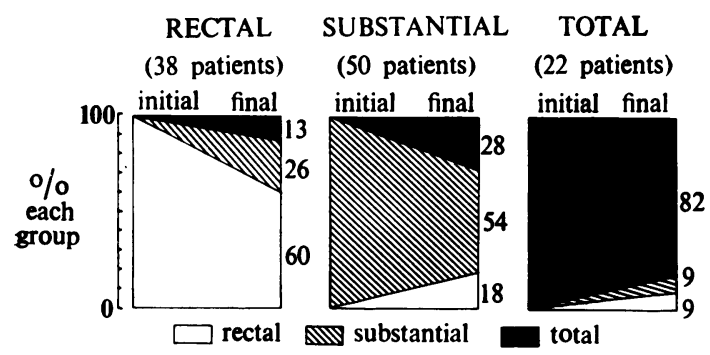

FIG. 5. The changes in extent of ulcerative colitis in 110 patients: 38 with disease initially restricted to the rectum, 50 with substantial colitis initially, and 22 with initial total involvement.

evidence of radiological disease in the colon in nine of these patients $(18 \%)$; but, by contrast, in 14 patients $(28 \%)$ the colitis had spread to involve the whole colon at the time of their final barium enema.

Finally, Fig. 5 shows that 22 patients were followed up after an initial barium enema which showed total involvement of the colon and rectum by ulcerative colitis. The vast majority of these patients (19 out of 22) showed evidence of total involvement right up to the time of their final barium enema.

It would therefore appear that both progression and regression of ulcerative colitis frequently take place, as judged by repeated radiological examinations. However, it must be stressed that progression of the disease is far more common than regression, and that once an area of bowel becomes involved by colitis, it rarely returns to normal.

\section{DISCUSSION}

Previous attempts to evaluate the radiological signs of ulcerative colitis have encountered considerable difficulties, and this has been for a number of reasons. Some authors have failed to define clearly their clinical and radiological criteria (Welin, 1963; Berenbaum, 1964) whilst some have performed excellent detailed studies but on a small selected group of patients (Dick, Berridge, and Grayson, 1959). Others, who have studied larger groups of patients, have failed to use statistical or actuarial methods to analyse their data (Kalil and Robbins, 1949), or have confined their attention to a single radiological appearance (Brooke and Sampson, 1964).

In our attempt to relate the radiological appearances of ulcerative colitis to the clinical state of the patient, we have been fortunate in several respects. Not only do we have available for study a large, well defined group of colitic patients, but in addition we have been able to obtain precise information about these patients by means of detailed case records which have been kept during the past 15 years. This has enabled us to relate individual radiological signs to the clinical state of the patient at the time, a most important step, since the radiological appearances can vary considerably in the individual patient in as little as a few weeks.

We have confined our attention in this study to a small number of radiological signs. Many other signs have been excluded, because previous observer variation studies have shown them to be unreliable (Geffen et al., 1968). For clearly there is little to be gained from a detailed actuarial and statistical analysis of signs which are in themselves open to serious degrees of observer variation.

RELATIONSHIP TO DURATION OF SYMPTOMS For the purpose of this analysis, an 'early' sign is interpreted as being a sign which has a significantly higher incidence during and immediately after the first attack of colitis than at any other stage of the disease. Conversely, a 'late' sign is one which has a significantly higher incidence 10 or more years after the onset of symptoms than in any of the earlier stages of the disease.

When so defined the only 'early' sign noted during the course of this survey was ulceration; although double contour and fine serration were also more frequently present during the early stages of colitis, the increased incidence of these signs was not statistically significant.

These findings are not inconsistent, for a finely serrated contour probably represents scattered tiny ulcers, and a double contour probably represents confluent areas of ulceration. Similar findings have been noted by other workers (Kadrnka and Audéoud, 1936; Hodges, 1944; Kalil and Robbins, 1949), who have also stressed the importance of fine serration as an 'early' radiological sign in proximal areas of the colon which may be subsequently involved as the disease spreads.

The radiological appearances which were more frequently seen in this survey during the late stages of the disease were shortening and narrowing of the colon together with impairment of the ability of the normal colon to distend as it is filled with barium. These appearances are those of the classical 'lead pipe' colon, and in this respect our experiences confirm those of other workers.

But it should not be thought that these appearances are necessarily diagnostic of longstanding colitis. These are common signs and they may be present at any stage of the disease; indeed up to onethird of patients may show a short, narrow colon within 12 months of the onset of symptoms. 
RELATIONSHIP TO COLITIC ACTIVITY One of the surprising features of this survey was the large number of signs whose incidence was totally unaffected by the activity of the patient's colitis at the time of the barium enema. This is all the more surprising since we have taken considerable pains to record the activity of each patient's colitis at the time. We had, for example, previously considered that polyps were a sign of active and severe disease; but this survey shows that they are far more common than we had supposed, being found in over $20 \%$ of the enemas performed whilst the patient was in remission. This finding is perhaps not entirely unexpected, for in a previous survey (de Dombal, Watts, Watkinson, and Goligher, 1966) examination of operative specimens showed that pseudopolyposis was far more extensive than we had imagined clinically.

Nevertheless, some signs were associated with active disease, notably ulceration, which was significantly more common in attacks than in remission, and whose incidence varied significantly with the severity of attack. Double contour, a rare sign, was almost always seen in association with severe attacks, but the small numbers involved make statistical analysis difficult.

SHORT-TERM PROGNOSIS The possibility of determining the prognosis of a patient with ulcerative colitis by a study of the radiological appearances has provoked considerable interest. Previous authors have, in the main, attempted to base a prognosis upon serial $x$-ray examinations by showing whether radiological appearances were reversible or irreversible. Both Welin (1963) and Walker and Curtis (1965) considered pseudopolyposis to be an irreversible change, and hence associated with a poor prognosis.

However, Brooke and Sampson (1964) find that the most important sign in prognostic terms was ulceration, which could be best seen on the plain film of the abdomen. They claim that this sign provides evidence of impending colonic disintegration, and consider it to be an indication for surgery.

The present survey provides no evidence whatsoever that any one single radiological sign gives more than a rough guide to prognosis in the individual patient. However, an accurate guide to the shortterm individual prognosis can be obtained by consideration of five radiological signs in combination, namely, a decrease in colonic tone, fine serration, ulcers, a double contour, and pseudopolyposis. Where three or more of these signs are present, then the outlook for the patient is extremely poor.

It would be possible to regard this combination of signs as an indication for surgery, but in practice this would be somewhat misleading, for almost all of these patients were in a severe attack of colitis at the time, almost all had total involvement, and thus the majority of these patients had other, more pressing indications for surgery. Nevertheless, we believe that a study of these five radiological signs will give a fairly helpful prognosis for the individual patient in the short term; and where three or more signs are present, then surgery at an early date should be seriously considered.

LONG-TERM PROGNOSIS Perhaps the most surprising feature of the whole survey has been our total failure to base any sort of accurate long-term prognosis on the detailed radiological findings at barium enema examination. Of all the signs which so profoundly influenced the prognosis over the next few months, none appeared to extend its influence beyond this period of time.

However, it must be stressed that radiological investigations can still be of considerable value in determining the long-term prognosis, even though no one sign, or group of signs, is used, because the prognosis in the long term depends to a considerable degree upon the extent of involvement of the colon by the disease process.

Nevertheless, the questions which remain are these. Is the extent of involvement constant throughout the course of the disease, being largely predetermined during the first attack? Or, conversely, is colitis a dynamic disease, in which the extent of involvement is constantly liable to change? Furthermore, if this latter view is correct, in what proportion of patients with colitis will such a change in the extent of the disease take place?

During the last 20 years, several surveys have attempted to deal with this problem. Ricketts, Kirsner, and Palmer (1948) were able to follow 46 patients by means of repeated barium enemas. They found that the disease remained static in 30 patients $(65 \%)$, was progressive in $24 \%$, and regressive in only $11 \%$; and they somewhat surprisingly suggest that the extent of bowel involved by colitis usually remains relatively constant.

Sloan, Bargen, and Gage (1950), reviewing 2,000 cases of ulcerative colitis, draw similar conclusions, but the authors do not state what percentage of their group were followed up by means of repeated barium enemas. It may well be that the 231 patients in whom changing extent of colitis was noted represent a considerable proportion of those patients who were followed up by serial radiographs.

Edling and Eklöf (1960 and 1961) analysed 238 patients with ulcerative colitis, of whom no fewer than 154 patients were investigated radiologically on more than one occasion. Citing their own evidence, and that of Ricketts and Sloan and their colleagues, 
they claim that the prognosis in ulcerative colitis is not influenced by the extent of disease, and further claim that the extent of involvement is (in the vast majority of cases) determined at an early stage of the disease.

In the light of our own experience we cannot agree with this view. During a relatively short period of follow up we have noted increasing colonic involvement in almost one third of our patients, and we have been particularly impressed by this tendency for the disease to extend proximally in serial barium enemas.

The relative infrequency of radiological regression in our patients is interesting. This is probably due to the fact that we have restricted our use of this term to patients in whom previously affected areas of bowel have subsequently shown no abnormality whatsoever on a subsequent barium enema. We have not included in this group patients in whom radiological improvement has taken place on serial enemas, for this, we feel, represents healing of the structurally damaged bowel, and not true regression of the disease.

In short, the whole picture of ulcerative colitis in our patients, both on clinical and radiological grounds, is one of a disease which is frequently progressive, involving greater and greater areas of the colon as time goes on. Moreover, as we have become only too well aware recently, an increase in the extent of the diseased bowel implies a change for the worse as far as the patient's prognosis is concerned.

\section{SUMMARY}

This paper presents an evaluation of the clinical significance of the radiological signs of ulcerative colitis. Three hundred and forty barium enemas were studied and the findings compared with the clinical pattern of colitis in each instance. Four clinical parameters were studied: the duration of colitic symptoms, the activity of disease at the time, and the short- and long-term prognoses.

Ulceration, fine serration, and double contour were more commonly seen in the early stages of colitis, and a short, narrow colon was more frequently seen in the late stages of the disease.

The incidence of many signs was unaffected by the activity of colitis. However, ulcers and a double contour were associated with attacks of colitis, and in particular with severe attacks.

Five signs carried a poor short-term prognosis: these were a decrease in tone, ulcers, fine serration, double contour, and polyps on the post-evacuation film. When three or more of these signs were present, two-thirds of patients died or came to surgery within one year.

No single sign or combination of signs gave an accurate individual long-term prognosis. The factor which determines this is the extent of involvement by the disease. Proximal extension of the disease process was noted in no less than one-third of 110 patients. It is emphasized that such a change in the extent of diseased bowel frequently implies a change in prognosis for the patient.

\section{REFERENCES}

Beranbaum, S. L. (1964). Roentgenologic diagnosis of idiopathic, nonspecific ulcerative colitis, with special reference to early manifestations. Dis. Colon Rect., 7, 135-146.

Brooke, B. N., and Sampson, P. A. (1964). An indication for surgery in acute ulcerative colitis. Lancet, 2, 1272-1273.

de Dombal, F. T., Watts, J. McK., Watkinson, G., and Goligher, J. C. (1966). Local complications of ulcerative colitis: stricture, pseudopolyposis, and carcinoma of colon and rectum. Brit. med. J., 1, 1442-1447.

Dick, A. P., Berridge, F. R., and Grayson, M. J. (1959). The pathological basis of the radiological changes in ulcerative colitis: a study of cases treated by colectomy. Brit. J. Radiol., 32, 432 449.

Edling, N. P. G., and Eklöf, O. (1960). A roentgenologic study of the course of ulcerative colitis. Acta radiol. (Stockh.), 54, 397-409.

_- - - (1961). Radiologic findings and prognosis in ulcerative colitis. Acta chir. scand., 121, 299-308.

Geffen, N., Darnborough, A., de Dombal, F. T., Watkinson, G., and Goligher, J. C. (1968). The radiological signs of ulcerative colitis: an assessment of their reliability by means of observer variation studies. Gut, 9, 150-156.

Hodges, F. J. (1944). 'Near misses' in $x$-ray diagnosis. New Orleans med. surg. J., 96, 341-346.

Kadrnka, S., and Audéoud, R. (1936). Radiologie des colites ulcéreuses: signes directs et indirects. Arch. Mal. Appar. dig., 26, 369-412.

Kalil, T. H., and Robbins, L. L. (1949). Early roentgenologic changes in idiopathic ulcerative colitis. Radiology, 53, 1-10.

Ricketts, W. E., Kirsner, J. B., and Palmer, W. L. (1948). Chronic non-specific ulcerative colitis: a roentgenologic study of its course. Gastroenterology, 10, 1-15.

Sloan, W. P., Jr., Bargen, J. A., and Gage, R. P. (1950). Life histories of patients with chronic ulcerative colitis: a review of 2,000 cases. Ibid., 16, 25-38.

Truelove, S. C., and Witts, L. J. (1955). Cortisone in ulcerative colitis. Brit. med. J., 2, 1041-1048.

Walker, F. C., and Curtis, G. T. (1965). Irreversible changes of ulcerative colitis. Ibid., 1, 414-416.

Watts, J. McK., de Dombal, F. T., Watkinson, G., and Goligher, J. C. (1966a). Early course of ulcerative colitis. Gut, 7, 16-31.

,,---1 - (1966b). Long-term prognosis of ulcerative colitis. Brit. med. J., 1, 1447-1453.

Welin, S. (1963). Advances in roentgen diagnosis of ulcerative colitis. Acta chir. scand., 125, $482-484$. 